\title{
Achilles Tendon Repair Under Local Anesthesia
}

\author{
Andrej Čretnik \\ University Clinical Centre Maribor, Department of Traumatology \\ Slovenia
}

\section{Introduction}

Achilles tendon rupture is not a very common injury, but it has always attracted a great attention. Hippocrates is believed to first write about its treatment, but the first description of the Achilles tendon rupture can be found in the works of Ambrois Pare in 1575 (Bradley \& Tibone, 1990; Maffulli, 1999).

Despite many different studies and metaanalyses, there is no universal agreement about the optimal management strategy of acute total Achilles tendon rupture. Most authors prefer open surgical repair as it contributes to a low incidence of re-rupture, ranging from $1,4 \%$ to 2,8\% (Cetti et al., 1993; Inglis \& Sculco, 1981; Lo et al., 1997; Maffulli, 1999; Thermann \& Zwipp, 1989; Wills et al. 1986). Strong repair with the restored length and optional augmentation offers the possibility of early functional treatment (Carter et al., 1992). As it is associated with significant number of complications $(11,8 \%$ to $21,6 \%)$ as well as high costs, some authors advocate conservative treatment (Cetti et al., 1993; Kocher et al., 2002; Lea \& Smith, 1972; McComis et al., 1997; Nistor, 1981; Wills et al. 1986). High incidence of reruptures (12\% to $17 \%)$, lengthened tendon and loss of strength are the main arguments for the opponents to criticize this method (Cetti et al., 1993; Inglis et al., 1976; Inglis \& Sculco, 1981; Kocher et al., 2002; Lo et al., 1997; Maffulli, 1999; Wills et al. 1986, Washburn et al., 1992, Webb \& Bannister, 1999). There are more and more papers favouring functional conservative treatment, what can yield to better results according to the lower re-rupture rate and better functional results (Kangas et al., 2003; McComis et al., 1997; Thermann et al., 1995; Twaddle \& Poon, 2007; Willits et al., 2010).

Percutaneous repair (first described by Ma \& Griffith in 1977) seems to bridge the gap, combining the advantages of conservative and operative treatment (Assal et al., 2002; Bradley \& Tibone, 1990; Buchgraber \& Pässler 1997; Čretnik et al., 2004, 2005; Fitzgibbons et al., 1993; Lim et al., 2001). It has been criticised to be weaker than open repair (Hockenbury \& Johns 1990) and with higher re-rupture rate (Webb \& Bannister 1999). Biomechanical studies have shown significantly greater biomechanical strength of the proposed modified method (Čretnik et al. 2000), with the strength comparable to open procedures (Čretnik et al. 2000, Watson et al. 1999, Zandbergen et al. 2005). According to the significantly stronger repair functional postoperative treatment should be encouraged and as it can be performed in an outpatient manner and under local anesthesia there are almost no contraindications to the method (except hypersensitivity to lidocain) (Čretnik et al. 2004, 2005, 2010). 


\section{Tendon repair}

\subsection{Position \& material}

The procedure is performed with the patient prone and with the injured foot lying free on a table with the enabled manipulation of the foot from the neutral position to the maximal plantar flexion (see Figure 1). Regular cleaning and desinfection procedures are performed during pre-operative preparations.

In general 20 - 30 mililiters of lidocaine (without noradrenaline!) in a sterile syringe with a regular infiltration needle is used. No tourniquet is needed. Regularly no antibiotic or antithrombotic prophylaxis is given.

Resorbable thread - Vicryl (polyglactin) No.2, length at least $50 \mathrm{~cm}$ (Ethicon, Sommerville, New Jersey) on long (up to $15 \mathrm{~cm}$ ) semicurved (could be also straight or specially bent), at the end triangularly cut needles (HeliPro, Jesenice, Slovenia) is used (see Figure 2). Usually any other long needle can be used - the procedure can be performed more conveniently with two needles (at each end of the thread), otherwise the needle must be swapped from one end of the thread to another.

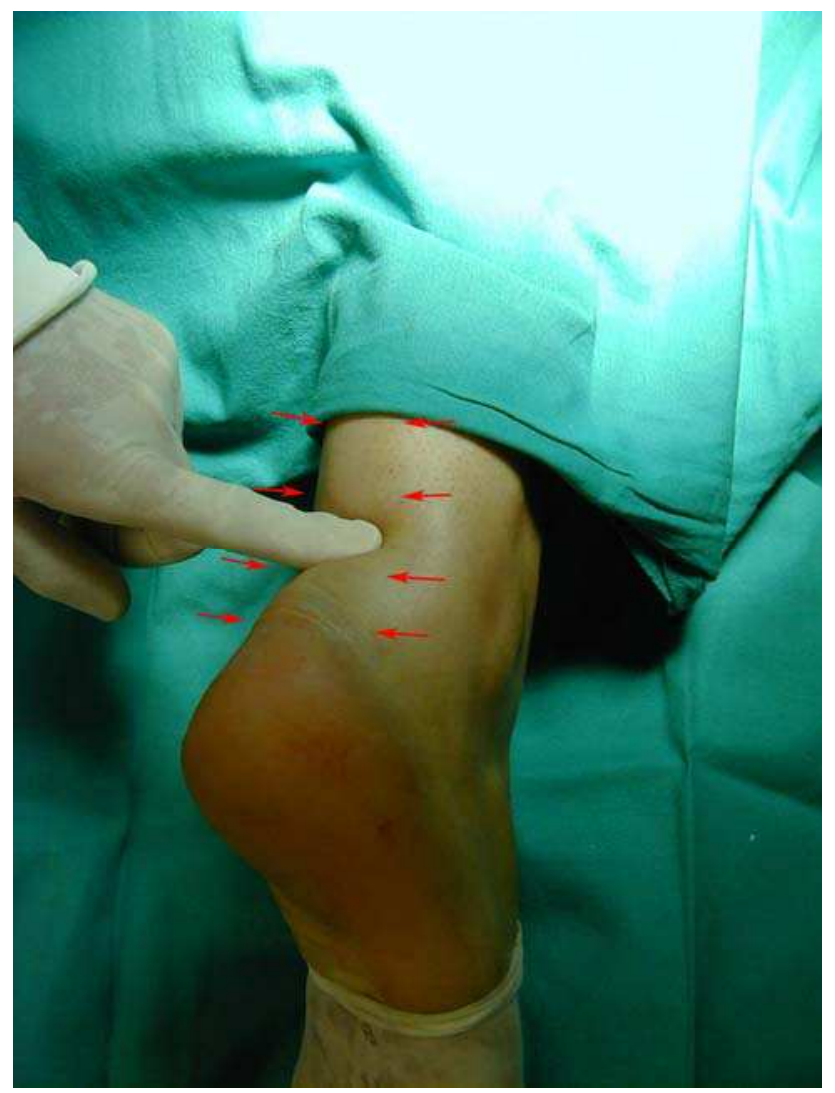

Fig. 1. (Palpating the gap) 


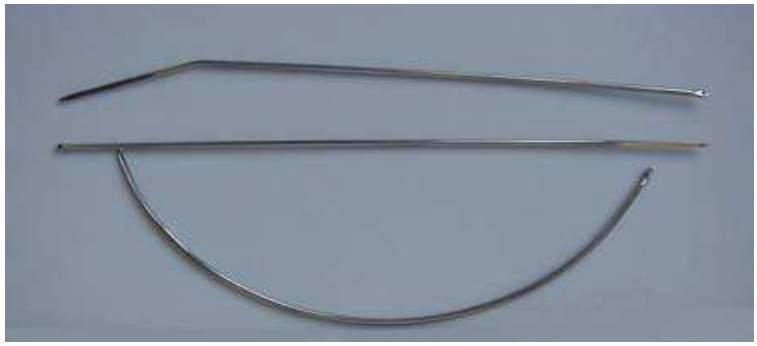

Fig. 2. (Needles)

\subsection{Operative technique}

Before starting, the rupture and diastasis (gap) must be localized (see Figure 1). After that, proximally (about five $\mathrm{cm}$ ) and distally (about four $\mathrm{cm}$ ) around the palpated gap, the cutis, subcutis and peritendineum are infiltrated at the marked points on the Figure 1. (see also Figure 3) All together there are eight puncture holes where the thread is later led. No other medications, nerve blocks or other types of anesthetics are given.

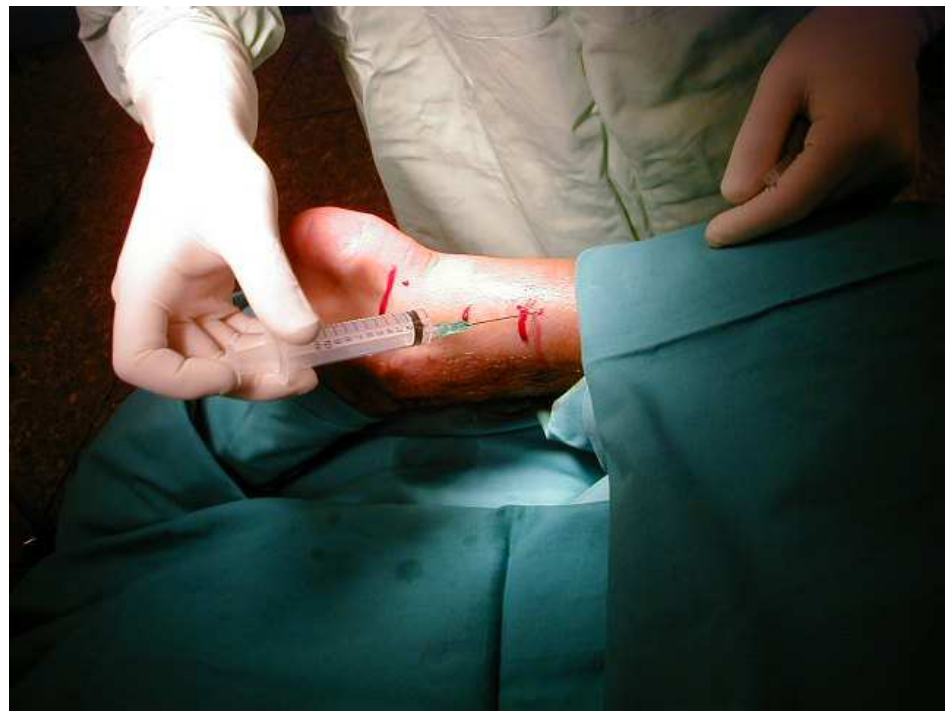

Fig. 3. (Infiltration with lidocaine)

Special attention must be paid to the lateral side, particularly proximally, where nervus suralis lies in the vicinity of the Achilles tendon and crosses it. According to the study of Citak et al. (2007) the lateral crossing of the sural nerve lies $8,7-12,4 \mathrm{~cm}$ proximally from the tuber calcanei. So the infiltration hole at the lateral side more than $9 \mathrm{~cm}$ proximally must not cross the lateral edge of Achilles tendon (it should lie even a little towards the inner area). Beside this, all the patient must be warned to report if any changes or sore pain are felt in this (nervus suralis) area during the puncture or infiltration. In that case, the puncture site must be moved for about half of or one $\mathrm{cm}$ towards the middle (the 
inner side) what can help to avoid sural nerve entrapment. In order to avoid direct sural nerve lesion and patient's comfort thinner infiltration needle (24-25 gauge) along with gentle injection could be used.

The procedure is started and finished medially and distally. First, the suture on the long, semicurved needle is transversely passed through the tendon (see scheme a on Figure 4), proceeding with the cross (diagonal) suture (see scheme $\mathbf{b}$ on Figure 4). If two needles (at each end of the thread) are used there is no need of swapping the needle from one end of

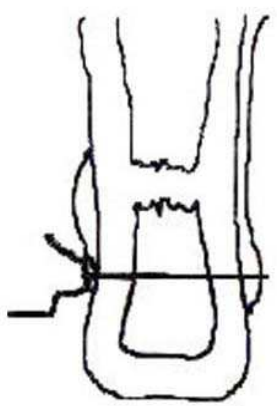

a

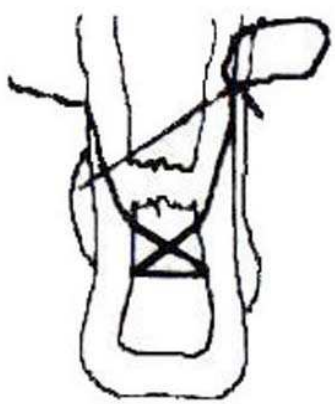

d

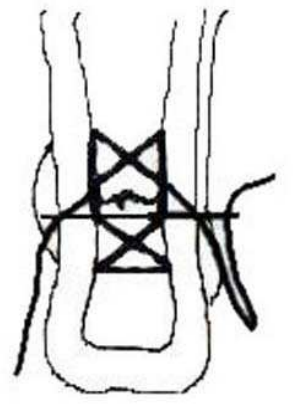

g

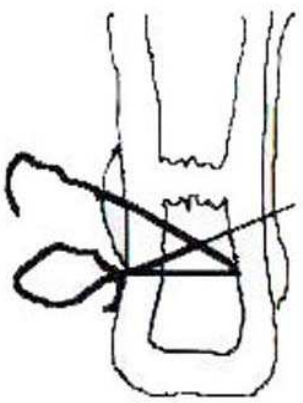

b
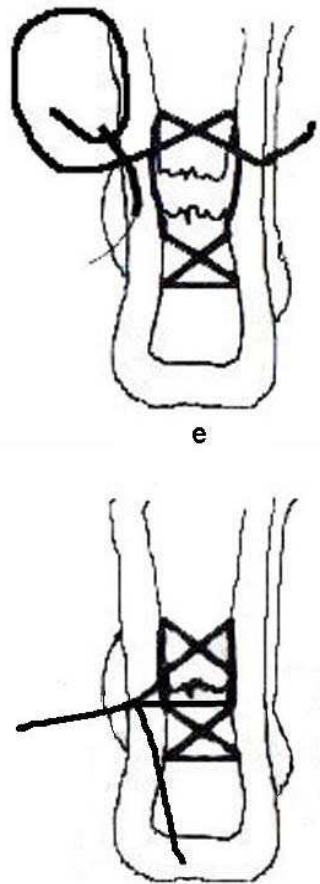

h

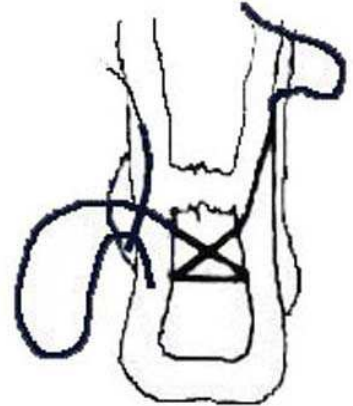

C
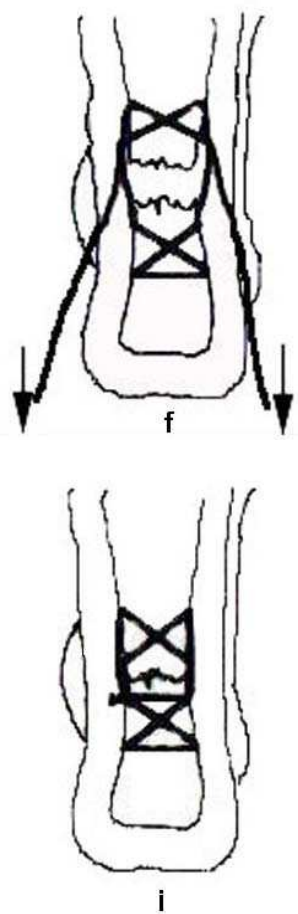

Fig. 4. (Scheme - from Journal of Foot and Ankle Surgery, 2004) 
the thread to another and if the needles are used simultaneously (the first left thrusted in untill the second passes it) no hitting or cutting the thread during the cross could occur (in this way only the metal (needle) can be hit). At every site of the first needle entrance or exit, the incision should be widened in longitudinal direction by pushing the scalpel blade (No.11) on the thrust-in needle to enable the surgeon to sink the thread subcutaneously (on the paratenon) when proceeding the suture through the same hole (see Figure 5). A small haemostat can also be used to widen the hole and enable the sinking of the thread through the same hole.

It is useful to always pull each side of the thread in a zig-zag manner after exiting each hole, so the thread can really slide and enable approximation of the torn ends at the end of the procedure. The thread is then led longitudinally, subcutaneously - extratendineously (see scheme $\mathbf{c}$ on Figure 4) and the next cross through the tendon is done proximally (see scheme d on Figure 4). After that, both ends are led extratendineously back through the third and second hole distally (see scheme e on Figure 4) and pulled symmetrically back with feeling until both ends of the torn Achilles tendon are completely approximated and the defect is no longer palpable (see scheme $\mathbf{f}$ on Figure 4).

After approximating the torn Achilles tendon ends, the lateral end of the thread is passed medially (see scheme g on Figure 4) (both ends of the thread must be held tightened at that time) where, after final tightening, the suture is tied (see scheme $\mathbf{h}$ on Figure 4). The knots are sunk (buried) subcutaneously through the previously widened second medial stab wound distally (see scheme $\mathbf{i}$ on Figure 4). At the end nothing can be seen on the surface, except eight small stab wounds and the folds of skin that later completely disappear (see Figure 6). Small stab wounds can be closed with very fine sutures but this is routinely not performed (Cretnik et al. 2004, 2005, 2010).

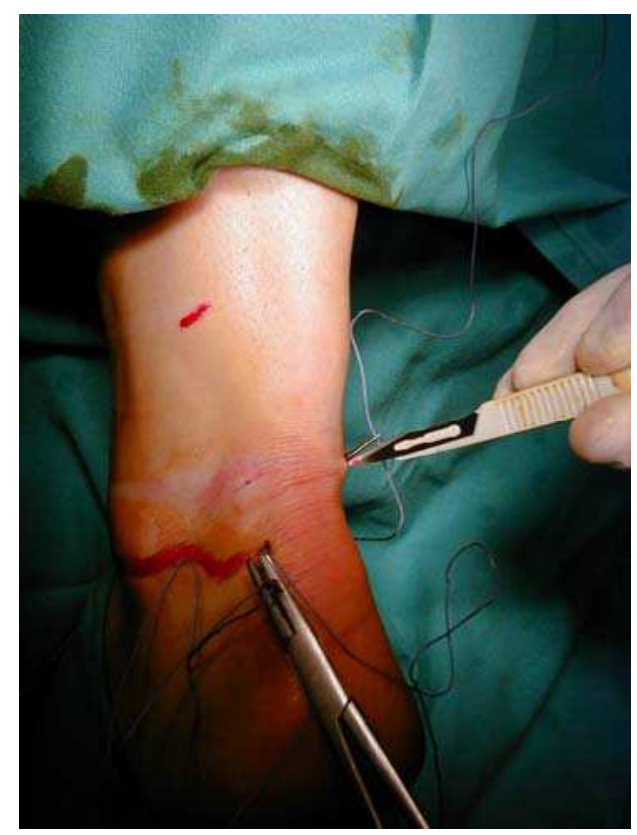

Fig. 5. (Widening the hole with blade No. 11) 


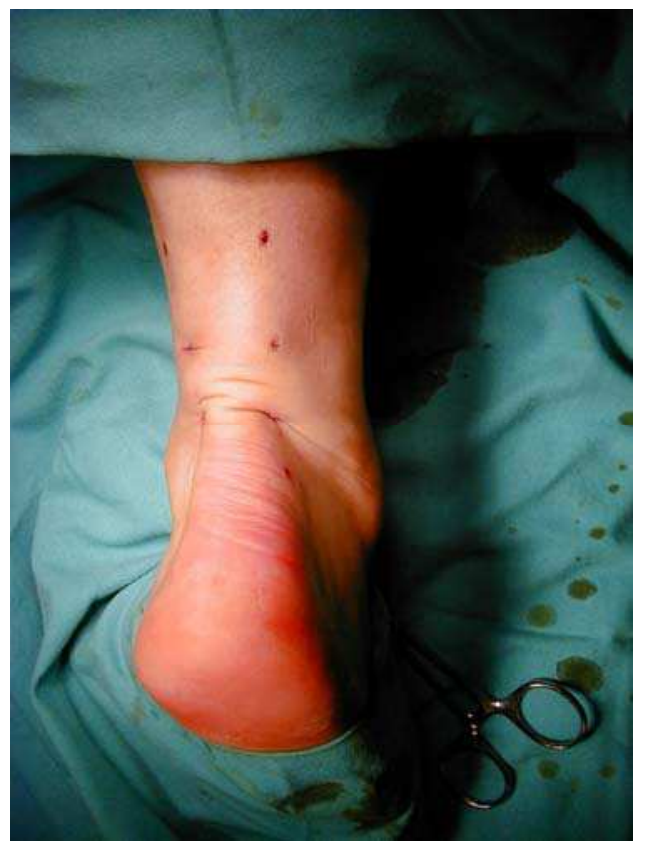

Fig. 6. (Final outlook)

Approximation can be intra- and postoperatively controlled by ultrasonography transducer is simply put into the sterile glove (or standard protection cover for arthroscopy) with the use of sterile gel or lidocaine gel (regularly used in urology). If any gap between the torn ends persists they should be pulled together with both ends of the thread further before the suture is tied (foot should be positioned in the maximal plantar flexion). Before final tightening it's very useful to gently manipulate with the foot in plantar and dorsal direction, so the thread can really be sunk at the surface of the tendon and the approximated ends secured with the tensioned thread without any loops or soft tissue captured. In the majority of cases disappearing of the gap and good approximation can be easily palpated but in the first cases until some experience is gained or if any doubt about that persist it's very helpful to use the ultrasonographic control.

\subsection{Postoperative procedure}

After the procedure, sterile dressing and a cast splint at the dorsal part with the foot in about 20 degrees of plantar flexion is applied. The first re-dressing is done the second day, when a functional orthosis made from softcast and stockinette is regularly applied for three weeks with the foot in about 20 degrees of plantar flexion (see Figure 7 and 8). It enables immediate plantar flexion and thus functional treatment with easy dressings and removal for hygienic procedures (washing). Patients should use crutches to walk and a careful weightbearing of approximately $5 \mathrm{~kg}$ is immediately allowed. In next three weeks progressive weightbearing up to $20 \mathrm{~kg}$ is allowed. No special heel or any special shoes are routinely used, although they can make walking easier (with supported heel). 


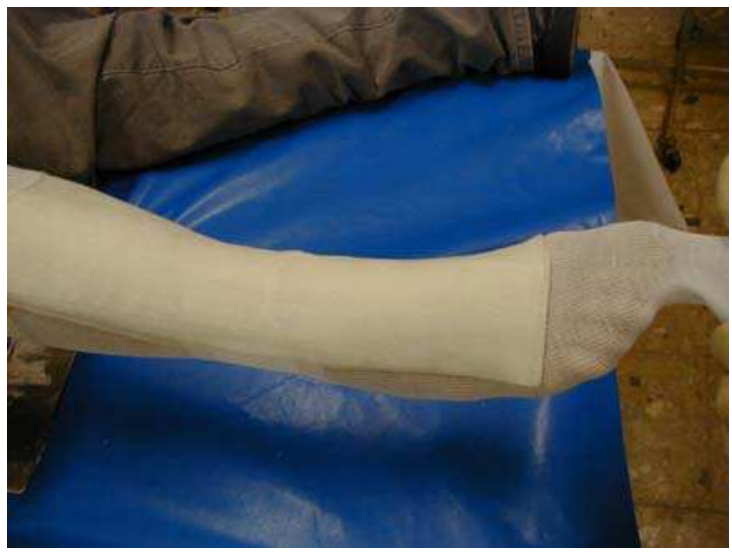

Fig. 7. (Softcast functional orthosis - preparation with stockinette)

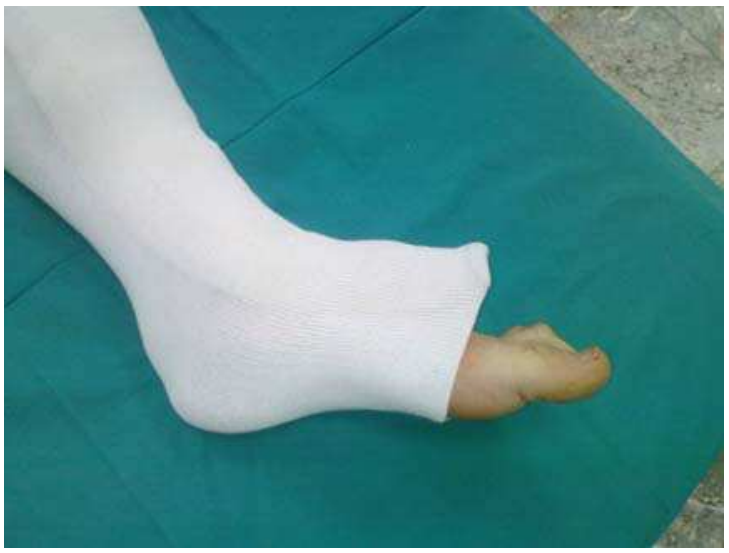

Fig. 8. (plantar flexion in orthosis)

After three weeks a new immobilization with the foot in neutral position (zero degrees of dorsiflexion) is applied. It's made in the same way to enable plantar flexion of the foot and to prevent dorsiflexion. It can also be made of cast, but softcast is much more convenient, lighter and water resistant. Patients keep walking with crutches and are allowed to bear weight as tolerated. They may walk with orthosis without crutches if they are able to and have no pain.

According to the principle of better healing if the ends are always sligthly tensioned, orthosis can be changed after two and four weeks and plantar flexion gradually diminished from 20 degrees to 10 degrees and at four weeks to zero degrees. If patients are walking with crutches and encouraged to gradually increase weightbearing, diminishing of plantar flexion to neutral position can be achieved with the softcast orthosis spontaneously, as it is becoming slowly more and more soften and allows reaching neutral position in four weeks without any change of orthosis and thus number of scheduled visits at clinics (and costs) can be further reduced. 
After six weeks the immobilization (orthosis) is removed and the patients are allowed to walk (without crutches) and start with careful rehabilitation until pain is felt (motion exercises, bathing, progressive resistance exercises, loads with elastic band ...). A special attention should be given to the correct pattern of walking (without limping). The patients are encouraged to start swimming and walking in the pool with weightbearing as much as tolerated in water. Stretching exercises are routinely allowed after eight weeks with careful increasing of the load. Raising on toes or heels is allowed twelve weeks after the operation and limited sports activities individually after three months with recommended full loading six months after operation. Indeed, many patients are starting with such activities(much) earlier with no complaints.

\subsection{Discussion}

There are many percutaneous closed (Čretnik et al., 2000, 2004, 2005; Gorschewsky et al., 2004; Ma \& Griffith, 1977; Majewsky et al., 2006; Webb \& Bannister, 1999) and semi-open methods (Amlang et al., 2006; Assal et al, 2002; Kakiuchi, 1995) proposed. They are four or six stab - incision techniques with one-aside pulling technique and consequently arose problem with non or malaligned stumps (so called fish-tail phenomenon) (Hockenbury \& Johns, 1990)). The proposed method, described above (Čretnik et al. 2004, 2005, 2010), is the only (at the moment) eight stab-incision technique and the only one with symmetrical pulling of both sides of the torn end, using double pulley principle, what enables appropriate adaptation without "fish- tail" phenomenon and with significantly reduced pulling - force needed. It enables also ultrasonographic control ad thus objectively confirmed approximation of the torn ends.

Biomechanical studies have confirmed significantly stronger repair with the proposed method in comparison to other percutaneous methods and comparable results to the open methods (Assal et al., 2002, Čretnik et al., 2000, Hockenbury \& Johns, 1990, Watson et al., 1995, Zandbergen et al., 2005). The ultimate load failure force with the open Kessler technique with two strands of Ethibond No. 1 was $85 \mathrm{~N}$ and with the Bunnell technique with the same strands was $93 \mathrm{~N}$. The ultimate load failure with the percutaneous $\mathrm{Ma}$ and Griffith technique with one strand of Vicryl No.2 was $111 \mathrm{~N}$ and with the proposed method (Čretnik et al. 2000) with the same material was 214 N. The ultimate load failure with the open Krackow Locking Loop with 4 strands of Ethibond No. 1 was $147 \mathrm{~N}$ and with 4 strands of Ethibond No. 2222 N. The strongest repair in human testing models was achieved with the open triple bundle technique with 6 strands of Ethibond No 1 (453N). The results showed comparable results of the proposed method with one resorbable strand of Vicryl No. 2 to open repair with the 4 strands of non-resorbable Ethibond No.1 with the Krackow Locking Loop technique (Čretnik et al., 2000,. Watson et al., 1995, Zandbergen et al., 2005).

The adequacy of apposition and fixation of torn ends seems to be crucial with all the methods and techniques. Complete rupture leads to retraction of the triceps surae and consequently to diastasis of the torn ends. As with conservative treatment the torn ends of the tendon stay apart (at the beginning in many cases good adaptation can be achieved with plantar flexion of the foot but the retraction occurs in next days, pulling torn ends apart and making diastasis), this brings the tendon to heal in the lengthened position and leads to the loss of normal tone and a weakening of the musculature (Čretnik et al., 2005, Inglis et al., 1976, Washburn et al., 1992). The gap is filled with fibrous tissue that is never as strong as 
the original tendon, contributing to a high incidence of rerupture (Webb \& Bannister, 1999; Wills et al., 1986). The review studies with a large number of patients show the rerupture rate with conservative treatment of $12 \%$ (Webb \& Bannister, 1999; Lo et al., 1997) to 13,4\% (Cetti et al., 1993) although there could be found reports on the functional conservative treatment with the lower incidence of the rerupture rate (Kangas et al., 2003; McComis et al., 1997; Thermann et al., 1995; Twaddle \& Poon, 2007; Willits et al., 2010).

Open repair enables the best visualization and adaptation of the torn ends and the possibility of augmentation with different types of strips and tendon parts to reduce the number of reruptures to minimum. It must be stressed that many times the approximation of the torn ends could not be achieved easy with open and particularly with percutaneous repair (Čretnik et al., 2005). The torn ends are often extremely friable and not as even, as we like to believe and there are many times difficulties to pull together the torn ends and achieve a good and firm adaptation, particularly using the techniques with simple loop or modified Bunnell's sutures (Buchgraber \& Pässler 1997; Ma \& Griffith, 1977; Webb \& Bannister, 1999). As shown in biomechanical studies above there are big differences in the strength of repair and consequently in the resistance ability during the healing process, particularly if functional treatment with the persistent tension to the torn ends is chosen. It is worth to be stressed therefore to choose the strongest method as possible. Stronger repair with good approximation of the torn ends provides healing with no elongation, low amount of the fibrous tissue, more resistance in functional postoperative treatment and thus low number of re-rupture rate.

Personal experience with the analysis of the percutaneously treated patients under local anesthesia in the period from 1991 to 2006 revealed 270 operated on and 267 finally analyzed patients $(98,8 \%)$ with $8(2,96 \%)$ re-ruptures (partial or complete) with only two patients needed to be re- operated on in an open way because of the diastasis of torn ends (the others were treated conservatively with ultrasonographic control and cast in plantar flexion for three weeks and additional three weeks in neutral position) with good final result in all cases (of re-ruptures) with no major or minor complications and with 216 patients $(80,8 \%)$ who returned to previous activities.

Percutaneous method is criticized to be a closed (blind) one, where the exact position of the torn ends and approximation cannot be visualized (Maffulli, 1999). Semi-open method was proposed as a solution, where (small) incision is made at the site of rupture and the approximation is checked under visual control (Kakiuchi, 1995). Special instruments were developed for this method (Achillon $\left.{ }^{\circledR}\right)$, Dresdner instrument), so the sural nerve injuries were almost completely reduced (Amlang et al, 2006; Assal et al. 2002;). Opening the site of a rupture the injury becomes an open one with all the risks and loss of haematoma with stimulating factors (mediators) (Growth Factors, Platelet Rich Plasma...) (Čretnik et al. 2005). However, as the torn ends are pulled apart, the gap between them can be palpated and the position of the ends thereby located. Addition of ultrasonography presents a precise tool for diagnosing the rupture and locating the gap and torn ends and control of approximation, what can be usually also clinically palpated (Čretnik et al, 2005). In our series with ultrasonographic control diastasis after the operation never exceeded 0,5 cm (Čretnik et al, 2005) what has been considered as an acceptable one in functional conservative treatment (Thermann \& Zwipp, 1989, Thermann et al., 1995). 
Prospective study has shown significiantly fewer major and total number of complications in the group of proposed percutaneous repairs in comparison with the group of open repairs. There were slightly more reruptures and sural nerve disturbances in the group of percutaneous repairs with no statistically significant difference. Functional assessment using various scores showed no statistically significant differences between both groups (Čretnik et al., 2005).

\subsection{Conclusion}

Proposed modified technique under local anesthesia seems probably more demanding but can be performed with the careful adherence to the instructions (particulars). It is very important to approximate the torn ends enough, so that the defect is clinically no longer palpable. Plantar flexion of the foot during reapproximation assists in this maneuver. Functional postoperative treatment with the simple softcast removable brace should be encouraged in all the operated on patients.

Long term results support the choice of the proposed modified percutaneous method under local anesthesia as the method that brings comparable functional results to open repair, with a significantly lower rate of complications.

\section{References}

Amlang, M.H.; Christiani, P.; Heinz, P. \& Zwipp, H. (2006). The percutaneous Suture of the Achilles Tendon with the Dresden Instrument. Operative Orthopädie und Traumatologie. Vol.18, No.4., pp. 287-299

Assal, M.; Jung, M.; Stern, R.; Rippstein, P.; Delmi, M. \& Hoffmeyer, P. (2002). Limited open repair of Achilles tendon ruptures. A technique with a new instrument and findings of a prospective multicenter study. J Bone Joint Surg 84A:161-170

Bradley, J.P. \& Tibone, J.E. (1990). Percutaneous and open surgical repairs of Achilles tendon ruptures. A comparative study. Am J Sports Med, 18: 188-195

Buchgraber, A. \& Pässler, H.H. (1997). Percutaneous repair of Achilles tendon rupture. Immobilization versus functional postoperative treatment. Clin Orthop 341: 113-122

Carter TR, Fowler PJ, Blokker C. (1992). Functional postoperative treatment of Achilles tendon repair. Am J Sports Med 20: 459-462

Cetti R, Christensen SE, Ejsted R, (1993) al: Operative versus nonoperative treatment of Achilles tendon rupture. Am J Sports Med 21: 791-799,

Citak, M.; Knoblach, K.; Albrecht, K.; Krettek, C. \& Hufner T. (2007). Anatomy oft he sural nerve in a computer assisted model: implicationsfor surgical minimal-invasive Achilles tendon repair. Br J Sports Med, 41, 456-458

Čretnik, A; Žlajpah, L; Smrkolj, V. \& Kosanović, M. (2000) The strength of percutaneous methods of repair of the Achilles tendon : a biomechanical study. Med. Sci. Sports Exerc. 32:16-20,.

Čretnik, A; Smrkolj, V. \& Kosanović, M. (2004). Percutaneous suturing of the ruptured Achilles tendon under local anesthesia. J. Foot Ankle Surg. Vol.43, No.2., pp. 72-81

Čretnik, A; Smrkolj, V. \& Kosanović, M. (2005). Percutaneous versus open repair of the ruptured Achilles tendon. A comparative study. Am. J. Sports Med. 33:1369-1379 
Čretnik, A; Košir, R. \& Kosanović, M. (2010) Incidence and outcome of operatively treated achilles tendon rupture in the elderly. Foot ankle int., Vol. 31, No.1, pp 14-18

Fitzgibbons, R.E.; Hefferon, J. \& Hill, J. (1993). Percutaneous Achilles tendon repair. Am J Sports Med 21: 724-727

Gorschewsky, O; Pitzl, M; Pütz, A; Klakow, A. \& Neumann, W. (2004). Percutaneous repair of Acute Achilles Tendon Rupture. Foot Ankle Int. 25:219-224

Hockenbury, R.T. \&, Johns, J.C. (1990). A biomechanical in vitro comparison of open versus percutaneous repair of tendon Achilles. Foot Ankle Int 11: 67-72,

Inglis, A.E.; Scott WN, Sculco TP. \& Paterson, A.H. (1976). Ruptures of the tendon Achillis. An objective assessment of surgical and non-surgical treatment. J Bone Joint Surg 58A: 990-999

Inglis, A.E. \& Sculco, T.P. (1981). Surgical repair of ruptures of the tendon Achillis. Clin Orthop 156: 160-169

Kakiuchi, M. (1995). A combined open and percutaneous technique for repair of tendon Achillis. Comparison with open repair. J Bone Joint Surg 77B: 60-63

Kangas, J.A.; Pajala, A.; Siira, P.; Hamalainen, M. \& Leppilahti, J. (2003) Early functional treatment versus early immobilization in tension of the musculotendinous unit after Achilles rupture repair: a prospective randomized, clinical study. J Trauma, 54, $1171-1180$

Kocher MS, Bishop J, Marshall R.; Briggs, K.K. \& Hawkins, R.J. (2002): Operative versus Nonoperative Management of Acute Achilles Tendon Rupture. Expected-value Decision Analysis. Am J Sports Med 30: 783-790,

Lea, R.B. \& Smith, L. (1972). Non-surgical treatment of tendon Achillis ruptures. J Bone Joint Surg 54A: 1398-1407,

Lim J, Dalal R, Waseem M. (2001). Percutaneous vs. Open repair of the Ruptured Achilles Tendon - A Prospective randomized Controlled Study. Foot Ankle Int 22: 559-568

Lo IK, Kirkley A, Nonweiler B. \& Kumbhare, D.A. (1997). Operative versus nonoperative treatment of acute Achilles tendon ruptures: a quantitative review. Clin J Sport Med, 7: 207-211

Ma GWC, Griffith TG. (1977). Percutaneous repair of acute closed ruptured Achilles tendon: A new technique. Clin Orthop 128: 247-255,

Maffuli, N. (1999). Rupture of the Achilles tendon. J Bone Joint Surg, 81A: 1019-1036

Majewski, M.; Rohrbach, M.; Czaja, S. \& Ochsner, P. (2006). Avoiding sural nerve injuries during percutaneous Achilles tendon repair. Am J Sports Med, Vol.34, No.5, pp. 793798

McComis, G.P.; Nawoczenski, D.A. \& DeHaven, K.E. (1997). Functional bracing for rupture of the Achilles tendon. Clinical results and analysis of ground-reaction forces and temporal data. J Bone Joint Surg 79A: 1799-1808

Nistor, L. (1981). Surgical and non-surgical treatment of Achilles tendon rupture. A prospective randomized study. J Bone Joint Surg 63A: 394-399,

Thermann, H. \& Zwipp, H. (1989). Achillessehnenruptur. Orthopäde 18: 321-335,

Thermann, H.; Zwipp, H. \& Tscherne, H. (1995). Functional treatment concept of acute rupture of the Achilles tendon. 2 years results of a prospective randomized study. Unfallchirurg, 98: 21 - 32 
Twaddle, B. C. \& Poon, P. (2007). Early motion for Achilles tendon ruptures: is surgery important? A randomized prospective study. Am J Sports Med. Vol.35, No.12, pp. $2033-2038$

Washburn SD, Caiozzo VJ, Wills CA.; Hunt, B.J. \& Prietto C.A. (1992). Alterations in the invivo torque-velocity relationship after Achilles tendon rupture. Further evidence of speed- specific impairment. Clin Orthop 279: 237-245

Watson, T.W.; Jurist, K.A.; Yang, K.H. \& Shen, K.L. (1995). The strength of Achilles tendon repair: an in vitro study of the biomechanical behaviour in human cadaver tendons. Foot Ankle Int. 16, pp. 191-195

Webb, J.M. \& Bannister, G.C. (1999). Percutaneous repair of the ruptured tendon Achillis. J. Bone Joint Surg, 81B: 877-880

Willits, K.; Amendola, A.; Bryant, D.; Mohtadi N. G.; Giffin, J.R.; Fowler, P.; Kean, C. O. \& Kirkley, A. (2010). Operative versus nonoperative treatment of acute Achilles tendon ruptures: a multicenter randomized trial using accelerated functional rehabilitation. J Bone Joint Surg Am. Vol.92, No.17, pp. 2767-2775

Wills CA, Washburn S, Caiozzo V. \& Prietto C.A. (1986). Achilles tendon rupture. A review of the literature comparing surgical versus nonsurgical treatment. Clin Orthop 207: 156-163

Zandbergen, R.A., de Boer, S.F.; Swiestra, B.A.; Day, J.; Kleinrensink, G.J. \& Beumer, A. (2005). Surgical treatment of Achilles tendon rupture: examination of strength of 3 types of suture techniques in a cadaver model. Acta Orthop. 76, pp. 408-411 


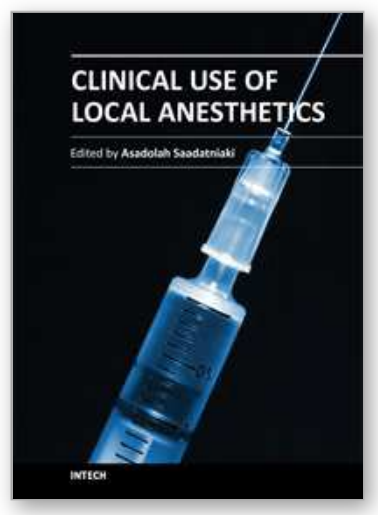

\author{
Clinical Use of Local Anesthetics \\ Edited by Dr. Asadolah Saadatniaki
}

ISBN 978-953-51-0430-8

Hard cover, 102 pages

Publisher InTech

Published online 23, March, 2012

Published in print edition March, 2012

Local anesthetics are being increasingly applied in different surgeries. Lower side effects of neuroaxial anesthesia, regional anesthesia, and field block, in comparison to general anesthesia (volatile and intravenous agents), are the main reasons why physicians prefer to conduct surgeries under local anesthesia, especially in outpatient and day care surgeries. It is important to emphasize the presence of an anesthesiologist, and vigilant monitoring of the homodynamic parameters, in decreasing a patient's anxiety, exerting other modalities for analgesia and increasing the safety margin in many procedures.

\title{
How to reference
}

In order to correctly reference this scholarly work, feel free to copy and paste the following:

Andrej Čretnik (2012). Achilles Tendon Repair Under Local Anesthesia, Clinical Use of Local Anesthetics, Dr. Asadolah Saadatniaki (Ed.), ISBN: 978-953-51-0430-8, InTech, Available from:

http://www.intechopen.com/books/clinical-use-of-local-anesthetics/achilles-tendon-repair-under-localanesthesia

\section{INTECH}

open science | open minds

\section{InTech Europe}

University Campus STeP Ri

Slavka Krautzeka 83/A

51000 Rijeka, Croatia

Phone: +385 (51) 770447

Fax: +385 (51) 686166

www.intechopen.com

\section{InTech China}

Unit 405, Office Block, Hotel Equatorial Shanghai

No.65, Yan An Road (West), Shanghai, 200040, China

中国上海市延安西路65号上海国际贵都大饭店办公楼 405 单元

Phone: +86-21-62489820

Fax: +86-21-62489821 
(C) 2012 The Author(s). Licensee IntechOpen. This is an open access article distributed under the terms of the Creative Commons Attribution 3.0 License, which permits unrestricted use, distribution, and reproduction in any medium, provided the original work is properly cited. 